\title{
Moving towards sustainable human capital development for Malaysian automotive industry
}

\begin{abstract}
This paper presents the efforts taken to have sustainable human capital development for the automotive industry in Malaysia by Malaysia Automotive Institute (MAI). The efforts must be driven by industry and it should consider the technology trends, market demand and government policy. MAI as a focal point for the automotive industry should create a platform for educators and industry players to come together to discuss the way forward in human capital development. Continual learning should be encouraged for the existing workers in the automotive industry to maintain their productivity and competitiveness.
\end{abstract}

Keyword: Human capital development; Automotive industry; Malaysia 